\title{
BETAINE SUPPLEMENTATION FOR VARIOUS CLINICAL DISORDERS
}

\author{
JAYALAKSHMI M, VANITHA V*
}

Department of Biochemistry, School of Life Sciences, Vels University, Chennai - 600 117, Tamil Nadu, India. Email: vanitha.sls@velsuniv.ac.in Received: 21 February 2017, Revised and Accepted: 24 March 2017

\begin{abstract}
Betaine is distributed widely in animals, plants, and microorganisms and rich dietary sources include seafood, especially marine invertebrates. Betaine is $\mathrm{N}$-trimethylated amino acid called as glycine betaine. It is a by-product. Betaine aldehyde is produced when choline dehydrogenase acts on choline, then betaine aldehyde is oxidized to form betaine by aldehyde dehydrogenase. Metabolic derived betaines possess various functions in our body in which they act as methyl donor which helps in liver function, detoxication, and cellular functions. It plays an important role in fat metabolism. Recent research found that betaine can convert homocysteine to cysteine thus they prevent heart disease. Choline is oxidized to betaine in liver and kidney. Intracellular betaine serves as an osmolyte that regulates cell volume and tissue integrity. Betaine not only plays as an osmolyte but also play a major role in the protection of the liver and other tissues. Consequently, it has been proposed that betaine has significant nutrient for prevention of chronic disease. Betaine has been shown to protect internal organs, improve vascular risk factors, and enhance performance. Databases of betaine content in food are being developed for correlation with population health studies. This review focuses on the aspects of wide research field with emphasis on a recent data relevant to various human diseases.
\end{abstract}

Keywords: Betaine, Detoxication, Homocysteine, Chronic disease, Choline, Trimethyl glycine, Glycine betaine

(c) 2017 The Authors. Published by Innovare Academic Sciences Pvt Ltd. This is an open access article under the CC BY license (http://creativecommons. org/licenses/by/4. 0/) DOI: http://dx.doi.org/10.22159/ajpcr.2017.v10i10.18075

\section{INTRODUCTION}

Betaine was early identified in the sugar beets (beta vulgaris) juice in the $19^{\text {th }}$ century and was commonly found in several other organisms. The physiologic action of betaine is that it performs as an organic osmolyte to protect cells under stress or as a catabolic source of methyl groups through transmethylation in many biochemical pathways [1]. The significant role of betaine in plants and microorganisms is to protect cells against osmotic inactivation. Betaine (glycine betaine or $\mathrm{N}, \mathrm{N}, \mathrm{N}$-trimethylglycine) is obtained from the diet or from its metabolic precursor choline [2]. Betaine is a major tissue osmolyte and plays a vital role in the metabolism of homocysteine, with betaine homocysteine methyltransferase (BHMT) catalyzing the remethylation of homocysteine to methionine.

Betaine is also known as glycine betaine, betaine anhydrous, or trimethylglycine (TMG) is a compound in the body and is involved in several functions such as liver function, cellular reproduction, and helping make carnitine. It also helps the body in homocysteine metabolism. Betaine is used to treat a genetic condition where too much homocysteine builds up in the body which is approved by the US Food and Drug Administration.

\section{BETAINE STRUCTURE}

TMG is an N-trimethylated amino acid and its quaternary ammonium exists as the zwitterion at neutral $\mathrm{pH}$. Strong acids such as hydrochloric acid convert TMG to various salts, with $\mathrm{HCl}$ yielding betaine hydrochloride.

$\left(\mathrm{CH}_{3}\right)_{3} \mathrm{~N}+\mathrm{CH}_{2} \mathrm{CO}_{2}+\mathrm{HCl} \rightarrow\left[\left(\mathrm{CH}_{3}\right)_{3} \mathrm{~N}+\mathrm{CH}_{2} \mathrm{CO}_{2} \mathrm{H}\right] \mathrm{Cl}-$

Demethylation of TMG gives dimethylglycine. Degradation of TMG yields trimethylamine, the scent of putrefying fish (Fig. 1).

\section{Synthesis of betaine}

Humans and animals can synthesize glycine betaine in a two-step process. The first step is the oxidation of choline to betaine aldehyde by the enzyme choline dehydrogenase. In the second step, betaine aldehyde is further oxidises with the enzyme betaine aldehyde dehydrogenase to produce betaine. An important major role of betaine in humans is to serve as a cofactor in methylation reactions, which occurs in all mammal cells.

\section{Other names of betaine}

2 (N,N,N-trimethyl)ammonium-acetate, betaína anhidra, bétaïne anhydre, betaine anhydrous, bétaïne de glycine, bétaïne de glycocoll, cystadane, glycine betaine, glycocoll betaine, glycylbetaine, lycine, oxyneurine, tmg.

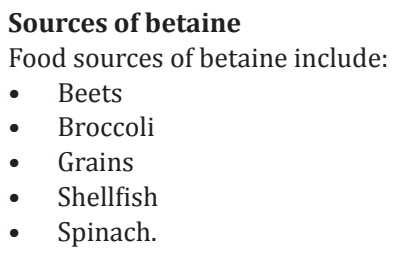

BETAINE CONTENT IN FOODS

\begin{tabular}{ll}
\hline Food & Betaine (mg/100 g) \\
\hline Quinoa & 630 \\
Spinach & 577 \\
Wheat bran & 360 \\
Lamb's quarters & 332 \\
Beetroot & 256 \\
\hline
\end{tabular}

\section{APPLICATIONS AND USES OF BETAINE}

Betaine is a natural alkaloid widely used as nutrition supplement in animal feed. As an essential nutrient betaine can be used in a wide variety of industries including food production, beverage, pharmaceutical, cosmetics, agriculture, animal feed, and various other industries.

- Betaine is used as natural preservative in food industry.

- Betaine is used in beverage industries.

- Betaine is used as active ingredient in pharmaceutical industries. It is used as medicine in various diseases. 


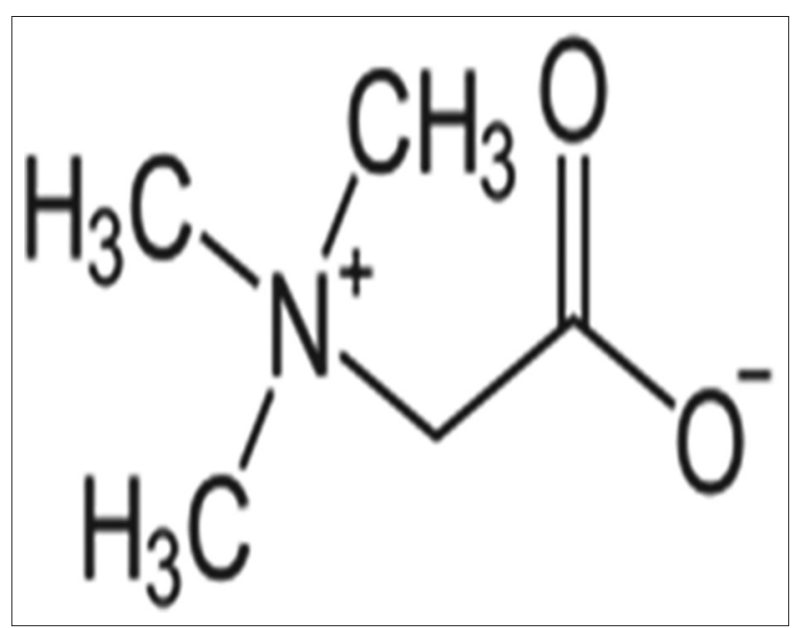

Fig. 1: IUPAC name: 2-trimethylammonioacetate

- Betaine acts as cleansing and water retaining agent in cosmetics and also in shampoo, soap, and toothpaste.

- In cattle and poultry feed betaine is used to improve the growth.

\section{BETAINE IN THE TREATMENT OF CANCER}

In recent years, many articles revealed that the growth of cancer cells can be inhibited by betaine in vitro. The primary biochemical function executed by betaine is the transfer of one-carbon moieties to maintain normal DNA methylation pattern in the body. Stabling of their methylation patterns is done by regulating the expression of protooncogenes and tumor suppressors; betaine exerts its anticancer action.

\section{LUNG CANCER}

About $28 \%$ of global cancer-related deaths and $15 \%$ of other diagnosed cancer deaths are caused by Lung cancer. Abnormal changes in DNA methylation leads to the activation of certain protooncogenes, such as c-Myc, and also to the inactivation of certain tumor suppressors, such as p16 [3] which can be observed in the development and progression of cancer. Some reports imply that certain dietary components affect the process of carcinogenesis, through DNA methylation. In fact, it has been shown that folate, as methyl group donors, riboflavin, vitamin B6, and vitamin B12, acts as cofactors in one-carbon metabolism are involved with DNA synthesis and DNA methylation and hence, they play a vital role in carcinogenesis and cancer risk; DNA global hypomethylation is associated with lung cancer. Researches shown that genetic code mechanism itself controls the methylation of DNA [4]. Betaine (B) maintains normal DNA methylation patterns [5] since it acts as a major methyl donor.

\section{BETAINE IN LUNG CANCER}

Humans obtain betaine from dietary choline. Choline is oxidized into betaine in a two-step enzyme-dependent reaction in liver and kidney. Betaine is involved in the synthesis of methionine, which acts as a major supplier of cellular cysteine through transsulfuration pathway for the synthesis of reduced glutathione which protects the cell from reactive oxygen species [6]. In choline-mediated one-carbon metabolism, signaling functions, cell membrane structural integrity, and neurotransmitter synthesis betaine plays a major role. Betaine is proved to be safe at a daily intake of dosage 9-15 g [6] which should not exceed. Betaine is nontoxic at all doses $(0-5 \%$ of the diet) which has determined from subacute and subchronic rat studies.

They revealed that in vitro $4 \%$ betaine could effectively decrease the viability of A549 lung cancer cells, which shows better effect in combination with C-PC. New anticancer drugs are developed with therapeutic target of the cancer cell cycle disturbances [7]. In cell proliferation, differentiation, and apoptosis cell cycle regulation betaine plays a vital role. The present investigation has been reported that the dysfunction of cell cycle regulation appears to be closely connected to tumor onset and development. Results from in vitro studies shown that there is some kind of interaction between C-PC and betaine that is still unknown. Since betaine transporters belong to the SLC36 group of proton-coupled amino acid symporters that are pH sensitive [8], it is possible that C-PC as a cysteine/methionine-rich protein [8] influences the uptake of betaine into the cells by adjusting the $\mathrm{pH}$ through the acid-base properties of its amino acid side-chains. The decrease of CPC fluorescence inside the cells when combined with betaine may be explained by C-PC slightly changing the conformation after changing its amino acid charge by donating/accepting $\mathrm{H}+$ ions. Furthermore, it might be possible that C-PC interacts with betaine itself since betaine is an amino acid-like compound, which can change its charge and transport over the cell membrane or interactions inside the cell.

Many studies proved that betaine and C-PC are easily applicable and powerful inhibitors of the A549 cell line growth. Thus, this combined treatment proved to be an effective inhibitor of the growth of A549 cells by preventing the cell cycle progression, reducing the cell viability, or enhancing the proapoptotic pathways.

\section{LIVER CANCER}

Liver cancer is commonly seen types of malignancy, especially in Asia and Africa, and it is the second most common cause of cancer death in China [9]. The progress of liver cancer is a multistep process of genetic alterations, involving the activation of proto-oncogenes and the inactivation of tumor suppressors, which lead to a continuous increase of uncontrolled cellular proliferation. Therefore, abnormal expression of related genes plays a crucial role in carcinogenesis. Transcription factor involved in regulating cell proliferation, differentiation, and apoptosis [10] is encoded by c-myc proto-oncogene. Abnormal changes in mRNA expression and DNA methylation of p16 and c-myc are therefore, the two important stimulatory factors in the development of liver cancer.

\section{BETAINE IN LIVER CANCER}

An important biochemical function of betaine is to transfer one-carbon moieties to maintain DNA methylation pattern in the body [11]. Thus, the betaine involved in preventing the liver cancer through regulating the expression of proto-oncogenes and tumor suppressors by stabling their mythylation patterns. Another major role of betaine is one-carbon metabolism which is important for liver function. Hepatic betaine is also act as a methyl donor. The expression of BHMT1 mRNA is at least 50 fold more abundant in mouse liver than any other tissue. A disturbance of hepatic one-carbon metabolism can lead to liver diseases including fatty liver, steatosis and hepatocellular carcinoma. Betaine contributes significantly to the transmethylation of homocysteine to methionine because the BHMT1 pathway is the most important route for the removal of homocysteine (cardiovascular risk factor) and catabolism of betaine.

\section{CERVICAL CANCER}

Cervical cancer is the third most common type of malignancy and the fourth leading cause of cancer-related mortality in women worldwide, accounting for $9 \%(529,800)$ of the total new cases and $8 \%(275,100)$ of the total cancer deaths among females in 2008 [12]. HeLa cell was the first human cell line established in culture, originated from a biopsy of cervical cancer tumor of a patient named Henrietta Lacks in 1951. Much of our understanding about fundamental cell physiology and cancer biology is due to HeLa cell research. Recently, two Nobel prizes have been awarded for research involving HeLa cells, namely, the link between human papillomavirus and cervical cancer [13]. Cervical cancer is usually a slowly developing neoplasm, and screening methods such as the Pap smear and HPV DNA test are available for early detection of precancer and cancer, hence, there is a substantiable scope for chemoprevention [14]. Apart from nutrients, antihormones, 
vitamin A analogues, and COX-2 inhibitors, extracts of medicinal plants also have shown in vivo and in vitro anticancer activity and have been evaluated for secondary chemoprevention or as complementary therapy in advanced cancer $[15,16]$.

\section{BETAINE IN CERVICAL CANCER}

A successful anticancer compound should kill or incapacitate cancer cells without causing excessive damage to normal cells. HeLa cells treated with the betaine showed a dose-dependent decrease in superoxide dismutase activities. On treatment with increasing concentration of betaine, there was a significantly rise in the mRNA and protein expression of Bcl-2 in a time dependent manner in HeLa cells [7]. Another three important genes involved in cell cycle regulation and cell apoptosis, Bax, p53, and Caspase 3, are all overexpressed in Hela cells. Moreover, the expression of Bax, p53, and Caspase 3 significantly increased in these cells after treatment with increasing concentration of betaine compared to untreated cells. The results indicated that upregulation of cyclin D1 expression promotes G1 phase arrest in Hela cells, and the p53-mediated cell cycle regulation pathway was dependent on cyclin D1. Betaine treatment in low dose groups enhanced cellular Bcl-2 expression and the Bcl-2/Bax ratio, thereby reversing drug resistance and inhibiting cell apoptosis. However, betaine in high concentration may cause damage to HeLa directly, and trigger apoptosis through Caspase 3 signaling pathway and further promote necrosis. Thus, treatment of betaine in high dose could inhibit the proliferation of drug-resistant cervical cancer cells and promote cell apoptosis (Table 1)

\section{HOMOCYSTEINEMIA}

Persons with an elevated serum homocysteine concentration are termed as hyperhomocystinemia or homocystinemia, and they have high risks of getting cardiovascular disease, stroke, Alzheimer disease, dementia, neural tube defects, and also some metabolic disorders [17]. An elevated level of fasting serum homocysteine and an elevated response of homocysteine after methionine loading (postmethionine) are independent risk factors for cardiovascular disease [18].

Betaine can improve both risk factors, and in humans with cardiovascular disease, there is a significant inverse relation between plasma betaine and homocysteine concentrations in fasting [19] and postmethionine states. Cardiovascular disease risk in healthy humans can be overcome by intake of betaine-rich diet. Elevated serum homocysteine is caused by an imbalance in the methionine cycle because of either genetic or nongenetic (e.g., Nutritional) defects that result in homocysteinemia. Parallel increase in intracellular S-adenosylhomocysteine $(\mathrm{SAH})$ is the result of chronic elevation of homocysteine and this, in combination with the S-adenosylmethionine (SAM):SAH ratio is predictive of cellular methylation status [20]. The activation of defective (mutant) enzyme activity with the relevant cofactor or its precursor (e.g., Folic acid or vitamins B-12 or B-6) is the treatment or preventive measures given to the patients, and it is based on the cause and severity of the defect. An alternative treatment is that pharmacologic doses of betaine or folic acid have been used to enhance the alternative pathway of homocysteine turnover.

\section{Homocystinuria}

Accumulation of homocysteine in the blood and urine leads to an inherited disorder namely homocystinuria. Homocystinuria patients usually lack a functioning cystathionine B-synthase, an enzyme which is responsible for breaking down of homocysteine. Due to a defect of this enzyme, an excess amount of homocysteine accumulates in the body which can be toxic at high levels. The symptoms of the disease usually noticed in the first few days of life and long-term consequences include learning disabilities, brittle bones, problems with vision and blood disorders can also be occurred. Homocystinuria is a long-term debilitating and life-threatening disease which may lead to blood clotting and heart problems and blood vessels and is associated with poor overall survival.

\section{DEFICIENCY}

Homocystinuria can be caused by a deficiency of cystathionine B-synthase (CBS), methylenetetrahydrofolate reductase (MTHFR) or methylcobalamin synthesis.

\section{PRESENTATION}

- Skeletal features

- Osteoporosis

- Arachnodactyly

- Kyphosis

- Short fourth metacarpal

- Growth arrest lines

- Genu valgum.

\section{CENTRAL NERVOUS SYSTEM}

- Mental retardation

- Psychiatric disturbances

- Extrapyramidal signs

- Seizures

- Abnormal electroencephalogram.

\section{VASCULAR SYSTEM}

- Vascular occlusions

- Malar flush

- Livedo reticularis.

\section{OTHER INVOLVEMENT}

- Fair brittle hair

- Thin skin

- Fatty changes in liver

- Myopathy.

\section{BETAINE TREATMENT}

Cystathionine is formed by the condensation of homocysteine and serine by CBS. Vitamin B-6 acts as a cofactor for CBS, and 50\% of patients with homocystinuria are responsive to vitamin B-6 therapy. It is difficult to treat Homocystinuria that is not responsive to vitamin B-6, but betaine, either alone or combined with other therapies, improves clinical symptoms, reduces homocysteine, and increases plasma methionine, serine, and cysteine concentrations [21]. Homocysteine gets accumulated in the central nervous system in CBS deficiency and may play a role in neurologic complications. Betaine treatment in children moderately lowers homocysteine in cerebrospinal fluid and increases serine and SAM concentrations [21]. Studies on

Table 1: Betaine treatment in different cancer types

\begin{tabular}{|c|c|c|}
\hline Disease & Clinical changes & Betaine treatment \\
\hline Lung cancer & Abnormal changes in DNA methylation & $\begin{array}{l}\text { Betaine maintains DNA methylation patterns: Acts as major methyl } \\
\text { donor }\end{array}$ \\
\hline Liver cancer & $\begin{array}{l}\text { Genetic alterations involve activation of proto-oncogenes } \\
\text { inactivation of tumor suppressors }\end{array}$ & $\begin{array}{l}\text { Regulation of expression of proto-oncogenes and tumor } \\
\text { suppressors stabling the methylation patterns }\end{array}$ \\
\hline Cervical cancer & Slowly developing neoplasm & $\begin{array}{l}\text { Betaine in high concentration trigger apoptosis through Caspase } 3 \\
\text { signaling pathway }\end{array}$ \\
\hline
\end{tabular}


Table 2: Betaine treatment in other diseases

\begin{tabular}{|c|c|c|c|}
\hline Disease & Clinical changes & Risk factors & Betaine treatment \\
\hline Homocysteinemia & Elevated homocysteine concentration & Risk of cardiovascular disease & $\begin{array}{l}\text { Betaine intake decreases homocysteine } \\
\text { concentration }\end{array}$ \\
\hline Homocystinuria & $\begin{array}{l}\text { Accumulation of homocysteine in } \\
\text { blood and urine }\end{array}$ & $\begin{array}{l}\text { Lack of cystathionine } \\
\text { B-synthase enzyme }\end{array}$ & $\begin{array}{l}\text { Betaine improves } \\
\text { homocysteineremethylation; lowers plasma } \\
\text { homocysteine }\end{array}$ \\
\hline Mild homocysteinemia & $\begin{array}{l}\text { Mildly elevated post methionine } \\
\text { homocysteine concentration }\end{array}$ & $\begin{array}{l}\text { Affects patients with } \\
\text { peripheral vascular disease }\end{array}$ & Betaine dependent remethylation occurs \\
\hline
\end{tabular}

NASH: Nonalcoholic steato hepatitis, AMP: Adenosine monophosphate

MTHFR deficiency [22] showed that betaine improves homocysteine methylation, lowers plasma homocysteine, normalizes very low plasma methionine, elevates SAM, and leads to clinical improvement.

\section{MILD HOMOCYSTEINEMIA}

Mild homocysteinemia is mostly seen than homocystinuria and is characterized by mildly elevated fasting or postmethionine homocysteine concentrations. Pooled data from many studies showed that mild homocysteinemia occurs in $9-42 \%$ of subjects below 50 years of age who have peripheral or cerebral occlusive arterial disease, myocardial infarction, or thromboembolism [23]. About 21\% of young patients with coronary artery disease, $24 \%$ of patients with cerebrovascular disease, and $32 \%$ of patients with peripheral vascular disease are found to have mild postmethionine homocysteinemia.

\section{BETAINE TREATMENT}

By ingesting a combination of vitamin B-6, folic acid, and betaine [22] or betaine (1.5-6 g/d) [18] alone can be the immediate treatment to reduce mild homocysteinemia. Betaine, but not folic acid, is effective at preventing an elevated level of postmethionine homocysteine concentrations [18]. In the liver and kidney, betaine-dependent remethylation occurs. In most cells, folate-dependent remethylation occurs. Serum homocysteine concentrations may be represented by the extrahepatic supply to the liver through folatere methylation and by the hepatic output through betaine remethylation [18]. Therefore, combined ingestion of folic acid and betaine may be the most effective method of lowering homocysteine.

\section{NON-ALCOHOLIC FATTY LIVER DISEASE (NAFLD)}

NAFLD is a kind of liver disease ranges from hepatic steatosis (accumulation of triglyceride inside hepatocytes) to nonalcoholic steatohepatitis (NASH) (necrosis and inflammation), with some people ultimately progressing to fibrosis and cirrhosis and liver failure. Because of its high prevalence in conjunction with obesity, diabetes, and insulin resistance, NAFLD is a hepatic manifestation of the metabolic syndrome and denotes an important cause of liver-related morbidity and mortality [24].

NAFLD is characterized by insulin resistance and dysregulated adipokine production, which is the central mechanism found in the development of steatosis and the transitional process to steatohepatitis in NAFLD [25]. Accumulation of fat in the liver leads to the imbalance in the uptake, synthesis, export, and oxidation of fatty acids. Adipose tissue is an important depot in the body to eliminate nonesterified free fatty acids.

\section{NASH}

NASH, a subtype of NAFLD, results in cirrhosis. In the US, NASH is an important cause of liver transplantation. Patient with obesity, diabetes, or hyperlipidemia NASH is commonly occurs. Frequently, the disease is discovered incidentally with asymptomatic elevation of liver aminotransferases on routine laboratory studies, or hepatomegaly on examination [26]. NASH has been described as an indolent disease leading to progressive fibrosis or cirrhosis in up to $30 \%$ of patients and is a cause of some cases of "cryptogenic" cirrhosis [27].

\section{BETAINE TREATMENT}

Betaine, a naturally occurring dietary compound, is synthesized in vivo from the oxidation of choline, and has several effects that may impact the natural history of NASH. These include:

1. It acts as a major role as a methyl donor in the conversion of homocysteine to methionine

2. Direct substitution for SAM for the direct methylation of phosphatidylethanolamine to phosphatidylcholine

3. Its downstream effects on oxidative stress and transsulfuration reactions

4. It involves in the activation of adenosine monophosphate activated protein kinase

5. Its properties as a lipotrope and osmolyte.

As a naturally acting agent, side effects with betaine would be expected to be minimal; however, it depends on the type of administration of betaine, as betaine anhydrous oral solution or as capsules. Betaine is a nature component of many foods and safe in doses ranging from 3 to $30 \mathrm{~g} /$ day; whereas other insulin sensitizers possess potential side effects, betaine may represent an ideal therapeutic agent for NAFLD (Table 2).

\section{BETAINE SUPPLEMENTATION}

The Indian definition for the dietary supplements as per the Food Safety and Security Act 2006 list down the ingredients that a product should have and it also specifies general properties of nutraceuticals [28].

- Betaine can be taken in supplement form or derived from food.

- The alcohol-induced fatty liver disease patients are suggested to take betaine normally between 1000 and $2000 \mathrm{mg}$, three times daily. It is needed to repair liver damage in certain cases, like with recovering alcoholics.

- People can use lower dose of betaine for nutritional support.

- Betaine HCL supplements are help in digestion that are available on the market. The suggested dose of betaine is between 650 and 2500 mg.

- People who want to develop their exercise performance, to increase their body composition, to get relief from body aches and pains may take between 1500 and $2000 \mathrm{mg}$ of betaine.

\section{CONCLUSION}

In the last decade, there has been growing interest in searching for cancer prophylactic and therapeutic effects of natural compounds. Many in vitro and some in vivo studies confirmed that betaine displayed a range of anticancer actions, such as inhibit carcinogen activation, cancer cell proliferation, angiogenesis, and metastasis. This review focused on unraveling the chemopreventive and therapeutic action of betaine and deciphered its molecular targets on human's different carcinoma cells, liver diseases, and other inherited disorders. The results showed that betaine exhibits tumoricidal effects and acts as a 
biological response modifier in cancer treatment by inducing apoptosis and cell cycle arrest in a dose- and time-dependent manner. In initial stages, it inhibits metabolic activation of carcinogens. In progression phases, it induces apoptosis, inhibits cancer cell proliferation and tumor metastasis. Many results provide new insights that betaine may serve as an alternative approach for cancer prevention and other disorders.

\section{REFERENCES}

1. Craig SA. Betaine in human nutrition. Am J Clin Nutr 2004;80(3):539-49.

2. Fischer LM, Scearce JA, Mar MH, Patel JR, Blanchard RT, Macintosh BA, et al. Ad libitum choline intake in healthy individuals meets or exceeds the proposed adequate intake level. J Nutr 2005;135(4):826-9.

3. Du YP, Peng JS, Sun A, Tang ZH, Ling WH, Zhu HL. Assessment of the effect of betaine on p16 and c-myc DNA methylation and mRNA expression in a chemical induced rat liver cancer model. BMC Cancer 2009;9:261.

4. Sherzay N, Chitakar E. Epigenetics: Effect of environmental factors on human genome. Int J Pharm Pharm Sci 2016;8:1-6.

5. Ying J, Rahbar MH, Hallman DM, Hernandez LM, Spitz MR, Forman MR, et al. Associations between dietary intake of choline and betaine and lung cancer risk. PLoS One 2013;8(2):e54561.

6. Ganesan B, Anandan R, Lakshmanan PT. Studies on the protective effects of betaine against oxidative damage during experimentally induced restraint stress in Wistar albino rat. Cell Stress Chaperones 2011;16:641-52.

7. Rupachandra S, Sarada DV. Induction of apoptotic effects of antiproliferative protein from the seeds of Borreria hispida on lung cancer (A549) and cervical cancer (HeLa) cell lines. Biomed Res Int 2014;2014:179836.

8. Bingula R, Dupuis C, Pichon C, Berthon JY, Filaire M, Pigeon L, et al. Study of the effects of betaine and/or c-phycocyanin on the growth of lung cancer A549 cells in vitro and in vivo. J Oncol 2016;2016:8162952.

9. Wang P, Meng ZQ, Chen Z, Lin JH, Ping B, Wang LF, et al. Diagnostic value and complications of fine needle aspiration for primary liver cancer and its influence on the treatment outcome-a study based on 3011 patients in China. Eur J Surg Oncol 2008;34(5):541-6.

10. Beer S, Komatsubara K, Bellovin DI, Kurobe M, Sylvester K, Felsher DW. Hepatotoxin-induced changes in the adult murine liver promote MYC-induced tumorigenesis. PLoS One 2008;3(6):e2493.

11. Duong FH, Christen V, Filipowicz M, Heim MH. S-Adenosylmethionine and betaine correct hepatitis $\mathrm{C}$ virus induced inhibition of interferon signaling in vitro. Hepatology 2006;43(4):796-806.

12. Jemal A, Bray F, Center MM, Ferlay J, Ward E, Forman D. Global cancer statistics. CA Cancer J Clin 2011;61(2):69-90.

13. Landry JJ, Pyl PT, Rausch T, Zichner T, Tekkedil MM, Stütz AM, et al. The genomic and transcriptomic landscape of a HeLa cell line. G3
(Bethesda) 2013;3(8):1213-24

14. Robert AW. Multistep tumorigenesis in the biology of cancer. Garland Sci 2007;11:399-462.

15. Gullett NP, Ruhul Amin AR, Bayraktar S, Pezzuto JM, Shin DM, Khuri FR, et al. Cancer prevention with natural compounds. Semin Oncol 2010;37(3):258-81

16. Vaidya AB, Vaidya RA. Roots of modern drugs in reverse pharmacology. Med Update 2010;20:871-9.

17. Seshadri S, Beiser A, Selhub J, Jacques PF, Rosenberg IH, D'Agostino RB, et al. Plasma homocysteine as a risk factor for dementia and Alzheimer's disease. N Engl J Med 2002;346(7):476-83.

18. Steenge GR, Verhoef P, Katan MB. Betaine supplementation lowers plasma homocysteine in healthy men and women. J Nutr 2003;133(5):1291-5.

19. Schwahn BC, Chen Z, Laryea MD, Wendel U, Lussier-Cacan S, Genest J Jr, et al. Homocysteine-betaine interactions in a murine model of 5,10-methylenetetrahydrofolate reductase deficiency. FASEB J 2003;17(3):512-4

20. James SJ, Melnyk S, Pogribna M, Pogribny IP, Caudill MA. Elevation in S-adenosylhomocysteine and DNA hypomethylation: Potential epigenetic mechanism for homocysteine-related pathology. J Nutr 2002;132 8 Suppl:2361S-6.

21. Dudman NP, Wilcken DE, Wang J, Lynch JF, Macey D, Lundberg P. Disordered methionine/homocysteine metabolism in premature vascular disease. Its occurrence, cofactor therapy, and enzymology. Arterioscler Thromb 1993;13(9):1253-60

22. Surtees R, Bowron A, Leonard J. Cerebrospinal fluid and plasma total homocysteine and related metabolites in children with cystathionine beta-synthase deficiency: The effect of treatment. Pediatr Res 1997;42(5):577-82.

23. Kishi T, Kawamura I, Harada Y, Eguchi T, Sakura N, Ueda K, et al. Effect of betaine on S-adenosylmethionine levels in the cerebrospinal fluid in a patient with methylenetetrahydrofolate reductase deficiency and peripheral neuropathy. J Inherit Metab Dis 1994;17:560-5.

24. Angulo P, Lindor KD. Non-alcoholic fatty liver disease. J Gastroenterol Hepatol 2002;17 Suppl: S186-90

25. Jou J, Choi SS, Diehl AM. Mechanisms of disease progression in nonalcoholic fatty liver disease. Semin Liver Dis 2008;28(7):370-9.

26. Ludwig J, Viggiano TR, McGill DB, Oh BJ. Nonalcoholic steatohepatitis: Mayo clinic experiences with a hitherto unnamed disease. Mayo Clin Proc 1980;55(7):434-8.

27. Powell EE, Cooksley WG, Hanson R, Searle J, Halliday JW, Powell LW. The natural history of nonalcoholic steatohepatitis: A follow-up study of forty-two patients for up to 21 years. Hepatology 1990;11(1):74-80.

28. Achary SR, Devla MN, Acharya NS, Kumar V. Dietary supplements: A legal status in India and in foreign countries. Int J Pharm Pham Sci 2011;3:7-12. 